four with anencephaly-an incidence of $2 \cdot 3$ per thousand births, which is typical in East Anglia. Of those with open neural tube defects, apart from anencephaly, the programme detected one fetus with a lesion that was confirmed by amniotic fluid $x$-fetoprotein, detected one that was not confirmed in this way, and missed two.

This screening programme was instigated with the expectation that it would prevent the birth of most live babies with open neural tube defects. After two years these expectations had not been fulfilled and, with the agreement of all those connected with the maternity service, the screening programme was discontinued.

Our disappointing results are probably not due to poor precision or accuracy of our $\boldsymbol{x}$-fetoprotein assay, nor due to atypical errors with scanning. Our main difficulty was that interpretation of the serum $\alpha$-fetoprotein concentration is critically dependent on the estimated gestational age. An error of one week in the estimate of maturity-for example, at 16 weeks-causes an alteration in the calculated multiple of the median of about $15^{\prime \prime}$. Accuracy of the estimation could be improved by earlier presentation at the clinic and by the use of newer scanners.

There were inevitable difficulties in getting samples and correct details, particularly those concerning gestation, to the laboratory and in returning results to the clinic in sufficient time to influence immediate management. Awaiting results, especially on repeat samples, caused concern to both patients and medical staff. Some problems of communication were experienced between this district and reference laboratories performing amniotic $\alpha$-fetoprotein assays, but this did not influence the outcome of any pregnancy in this series.

We believe that the correlation between concentrations of maternal serum $x$-fetoprotein and fetal open neural tube defects, anencephaly apart, is insufficiently close to justify this type of screening, certainly in parts of the country with a relatively low incidence of neural tube defects. Other similar hospitals, particularly in central and eastern England, should consider carefully whether to embark on, or to continue such a programme. A clear benefit to the patient or community, or both, should be apparent to justify screening because, cost and labour apart, many patients experienced considerable anxiety, particularly the relatively high number who required more than one serum estimation. Moreover, even if the screen was more specific for open neural tube defects, it might still preferentially detect fetuses that would perish spontaneously.

We thank Mr G Reynolds for performing the scans, Mrs R Philipson for taking blood, Mrs J Cooper for typing the manuscript, and Miss S Macaskill and Mr A B W Taylor for permission to review their patients.

\section{References}

1 Working Group on Screening for Neural Tube Defects. Report. London DHSS, 1979.

2 Brock DJH, Scrimgeour JB, Steven J, Barron L, Watt M. Maternal plasma alpha-fetoprotein screening for fetal neural tube defects. $B r \mathcal{F}$ Obitet Gynaecol 1978;85:575-81.

3 Wald NJ, Cuckle HS. Alphafetoprotein in the antenatal diagnosis of open neural tube defects. Br 7 Hosp Med 1980;23:473-89.

${ }^{4}$ Medical Research Council Working Party on Amniocentesis. An assessment of the hazards of amniocentesis. Br F Obstet Gynaecol 1978;85 suppl 2:1-41.

"Robinson HP, Fleming JEE. A critical evaluation of sonar "crown rump length" measurements. Br f Obstet Gynaecol 1975;82:702-10.

6 Campbell S. An improved method of fetal cephalometry by ultrasound. Fournal of ()bstetrics and Gynaecology of the British Commonwealth 1968 75:568-76.

(Accepted 8 fuly 1981)

\title{
An investigation into the management of bilateral leg amputees
}

\author{
CATHERINE M C VAN DE VEN
}

\begin{abstract}
Patients with bilateral high level amputations of the legs are rarely func ${ }^{\prime}$ ionally independent after their discharge from hospital. Eighty bilateral amputees were visited by a research physiotherapist, and information was obtained on their family circumstances, accommodation, mobility, and prostheses. A second questionnaire was completed by hospital staff on medical condition, assessments, rehabilitation, and total overall management.

The results showed that mobility was severely restricted; out of the 80 patients visited, only 65 could manoeuvre wheelchairs and 23 use prostheses. Accommodation presented difficulties: 34 homes had steps inside and 40 had steps outside. Of the 80 patients seen, 60 could not cope in the bath while 33 were unable to use the lavatory. Assessments and rehabilitation were lacking. There appeared to be little overall management, and hospital staff made only 36 visits to the patient's accommodation before discharge.
\end{abstract}

Queen Mary's Hospital and DHSS Limb Fitting Centre, London SW15 5PR

CATHERINE M C, VAN DE VEN, MCSP, superintendent physiotherapist

\section{Introduction}

About 5000 new patients with leg amputations are referred to the DHSS artificial limb and appliance centres each year. Of these, around $3500(70 \%)$ are over 60 , and $3750(75 \%)$ have lost their limbs through peripheral vascular disease or diabetes. ${ }^{1}$ Some $450(9 \%)$ of these new amputees have lost both legs; in half these cases the patients have had one leg amputated earlier, losing the remaining leg because of systemic disease. ${ }^{2}$

These figures do not include amputees who are not referred to limb fitting centres. Of the 100 amputees in this project, seven patients had never been to an artificial limb and appliance centre or a limb fitting centre.

Management of elderly amputees suffering from systemic diseases is often complicated by associated medical problems, such as hemiparesis and shortness of breath from heart or lung disease. $^{34}$ The problems are worse when the individual has a bilateral amputation, and the higher the level of amputation the more difficult and complicated the rehabilitation. ${ }^{5}$

To be of any use help must be realistic and within each patient's physical and mental capabilities. Independence in selfcare such as dressing, bathing, and using the lavatory has to be relearnt because of new physical circumstances, ${ }^{6}$ and patients and their families need to make many readjustments. ${ }^{7}$ 


\section{Method}

In 1971 I carried out an initial pilot survey, which investigated 25 elderly bilateral leg amputees. ${ }^{8}$ This indicated a need for a similar study in greater detail, and a two-year project was undertaken to investigate the rehabilitation, management, and functional independence of 100 bilateral leg amputees.

Patients were admitted to the study if they had bilateral above-knee or through-knee amputations, were 55 years or over, had become bilateral amputees within the previous three years, and were living within the South-west Thames region, either at home or in residential care.

Patients were found from the files of the DHSS limb fitting centres and artificial limb and appliance centres at Roehampton, Portsmouth, and Brighton. All general and geriatric hospitals within the region were contacted to try to find amputees who had never been referred to limb fitting centres.

The first 100 patients fulfilling the study criteria included 77 men and 23 women. Of the 96 who agreed to the investigation, 80 were visited. Eleven died before they could be visited, and five were too ill to be visited. An appointment was made to visit each patient in his place of residence by the research physiotherapist, who completed a questionnaire.

A second questionnaire was sent to each superintendent physiotherapist in charge of the hospital department where the amputees had been inpatients, with questions on the medical condition of the patient, duration of stay in hospital, assessment, and rehabilitation. Accurate information was not always available, but 59 out of the 96 questionnaires were fully completed, 27 were partially completed, and for 10 patients there was insufficient information. Good co-operation and willingness to help were given by all but one of the 47 hospitals approached.

The information from both questionnaires was analysed using the statistical package for the social science programme.

\section{Results and comment}

Of the 80 patients visited, 60 when interviewed had already retired, 16 stated that they were housewives and considered that they still worked, and only four were still employed (two part-time). Eighteen lived alone, 43 were living with family or friends, and 19 were living in residential care. Table I shows the type of accommodation.

TABLE I-Type of accommodation in which the 80 visited patients lived

\begin{tabular}{|c|c|c|c|c|c|c|c|c|}
\hline & & & & & & & & $\begin{array}{c}\text { No of } \\
\text { patients }\end{array}$ \\
\hline Houses $\quad \ldots$ & $\ldots$ & $\ldots$ & $\ldots$ & . & $\ldots$ & . & . & 24 \\
\hline Ground-floor flats.. & . & . & . & . & . & . & . & 19 \\
\hline Flats above ground floor & .. & .. & . & . & . & . & . & 5 \\
\hline \multirow{2}{*}{\multicolumn{8}{|c|}{ Sheltered accommodation: warden-assisted flats, residential care, }} & 7 \\
\hline & & & & & & & & 25 \\
\hline Total & . & . & . & . & . & . & . & 80 \\
\hline
\end{tabular}

\section{ACCOMMODATION}

Though some categories of housing appear to be easier to manage, with more space to move about, this was often not the case. Houses had flights of stairs, narrow doors, and the odd steps. Five groundfloor flats had steps up to the front door of the block of flats. Bungalows also had steps at front and back doors. Flats above the ground floor were served by lifts that broke down or were vandalised. Residential homes, although in some cases favourable inside, might be in remote areas. One was built on the side of a very steep hill making it almost impossible for amputees to go outside, and even with help it was difficult. Purpose-built flats or bungalows for the handicapped were probably the best solutions, giving amputees mobility with ease and security. Thirty-six patients stated that structural alterations had been necessary, such as moving a bathroom, lavatory, or shower downstairs; redesigning or building an extra room; giving more space; etc. This had required a surveyor, an architect, and a builder. Twenty amputees had had positive structural alterations carried out to their accommodation, but only 14 were happy with the final results-having succeeded in obtaining extra space. Sixteen patients at the time of the visit had had nothing done at all.
Those in council-owned accommodation appeared to obtain quicker alterations than owners of their own property or those who rented privately. Twelve of the 20 patients who needed alterations in council property were happy with the results, and only six had had nothing done. None of the four who needed alterations in privately rented property had had anything done at all by the time of the visit. Half of the amputees living in their own property had made successful alterations.

In some cases alterations proved impossible even if everybody (putient, local council, and family) had tried their best. Some properties were not structurally suitable for alteration. Many of the alterations took considerable time.

Mobility was one of the greatest problems. Most amputees lacked freedom to move around their property. Thirty-four of the 80 patients had steps indoors, while 12 living in houses could not manage the stairs and another five required help to negotiate them. Restricted mobility within the home led to lack of independence in self-care, such as bathing and going to the lavatory. Sixty patients had problems taking a bath (table II).

TABLE II-Problems with taking a bath

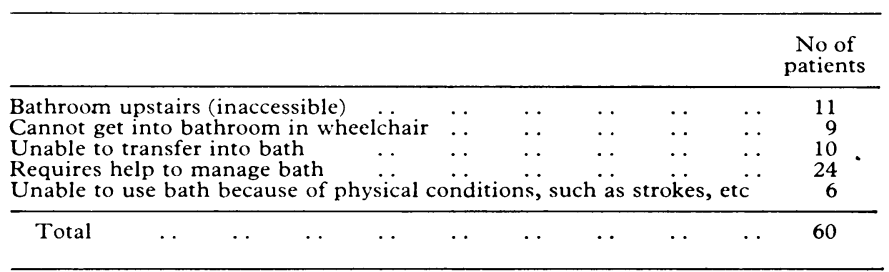

Lavatories did not present quite such problems, but 33 patients said they had difficulties: 22 could not reach them, seven lavatories being upstairs, four outside, and 11 too small to use safely. Eleven other patients had difficulties because they were suffering from other disabilities, such as hemiparesis, severe rheumatoid arthritis, etc. All 33 patients required and used commodes.

\section{APPLIANCES AND AIDS}

All 80 patients had the correct type of wheelchair for bilateral aboveknee or through-knee amputees, the rear wheels being set back thus preventing the tipping of the chair. ${ }^{6}$ Seventy-three said that these were suitable, and the remaining seven had only minimal problems, which could have been solved by a telephone call to the local artificial limb and appliance centre. Sixty-five manoeuvred their chairs with ease, but again steps caused problems-often making entering and leaving homes without help impossible. Of the 40 who had to negotiate steps to leave and enter their homes, 30 required help. Three patients living alone were completely trapped within their four walls.

Fifty-six amputees never went out alone, 26 never travelled as a passenger in a car, and only one used public transport. Only 28 amputees had been away from home since they had lost their second leg, and 17 of these had been on organised holidays for the disabled. These were much easier for the amputee, and there was trained help. Unfortunately for some it was also a little depressing, and sometimes the spouse of the amputee found it difficult to fit in.

Small aids such as bath boards, non-slip mats, and long-handled pick-ups had been supplied to 68 patients, most of whom used them regularly.

All 80 patients visited were asked about home assessments. Thirtysix stated that staff from the hospital had visited their place of residence before discharge, but only 10 patients had actually gone on their own home visits. Forty-five were seen by local authority staff after they had returned home. This appeared to be a general follow-up on behalf of the local community services.

\section{PROSTHESES}

Sixty-five of the 80 amputees visited had at one time had artificial limbs prescribed. Some possessed short rocker pylons, articulated pylons, and definitive limbs; others had only one pair of prostheses. Altogether 116 pairs of prostheses had been supplied to the 65 patients. When visited 29 amputees stated that they wore their prostheses but only 25 amputees were actually wearing them. 
Wearing and using prostheses are different concepts. Patients wearing artificial limbs put them on occasionally and walk in them sometimes. They do not have them on daily and do not rely on them for their mobility and lifestyle. Patients using artificial limbs put them on all day every day, and need them for their mobility and lifestyle. In this review 23 patients used their prostheses and six wore them. All 80 patients used their wheelchairs during the day, either all the time or combined with prostheses.

Of the 29 amputees who still had their prostheses, most could put them on, take them off, and walk indoors unaided (table III). Standing

TABLE III-Activities carried out unaided by the 29 amputees still owning their prostheses

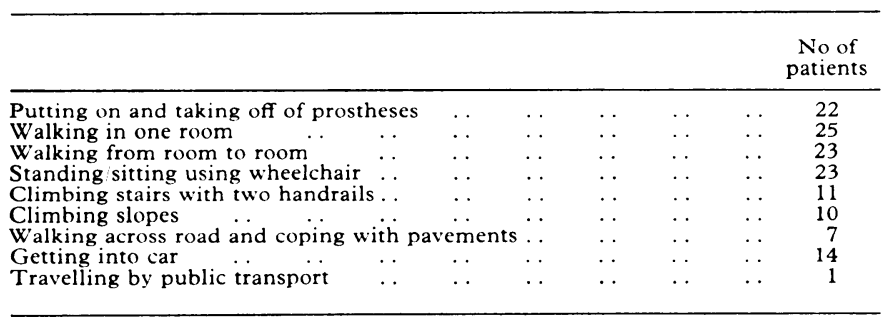

from sitting is difficult for bilateral amputees wearing prostheses. Chairs need arm rests and to be of a reasonable height (about 27 in or $40 \mathrm{~cm}$ ) for the patient to lever himself upright from sitting. The chair must also be stable. More patients preferred to use their wheelchair than a normal chair. Steps, stairs, slopes, the garden, going across the road, getting in and out of cars, and using buses, trains, etc, all reduced the number of patients succeeding without help.

Each patient was asked if he had ever seen other amputees wearing prostheses before getting his own. Fifty-nine said that they had: 55 had been given some explanation of limb-wearing, but 19 said they had known absolutely nothing. Forty-three had been advised and encouraged by medical staff to try artificial limbs, but 23 , who originally had been unilateral amputees, had just been sent back to the artificial limb and appliance centre or limb fitting centre without any extra explanation at all. These patients stated that as they had worn single artificial limbs everyone assumed they would receive another leg.

At the conclusion of each visit the patients were asked their opinion about their rehabilitation, management, prostheses, and home circumstances. Though some replies differed, almost every comment concerned mobility. Some, who said that they had many problems, were positive in their outlook towards their future, others were depressed; some could see no solution. Others were determined to make the best of their particular predicament. So much seemed to depend on the patients as individuals-their motivation, and the support received from family, friends, and, in some cases, social services.

\section{Medical information}

Information obtained from the hospital questionnaire was disappointing at times and also lacking in detail. The cause of the amputation was peripheral vascular disease in 83 of the 96 patients. In 54 the time lapse between amputations was six months or less, indicating that many patients did not have the chance to become fit and mobile before losing the second limb. The average period spent in hospital was 4.3 months. Many patients were suffering from other medical conditions-cardiovascular and respiratory problems $\left(30^{\circ} \mathrm{o}\right)$, osteoarthritis, rheumatoid arthritis, depression, or poor vision and hearing, etc.

Forty-eight patients had had preoperative physiotherapy and the same number were seen in the occupational therapy department for assessment for a wheelchair. Forty-seven had been seen by medical social workers. In four cases no hospital medical social worker existed. Eighty-three patients had had regular postoperative physiotherapyfor example, chest physiotherapy, strengthening exercises, transfers, mobilising and increasing joint ranges, etc. In 17 stated cases hip flexion contractures were present. The degrees of flexion were generally unspecified. Sixty-one patients attended the occupational therapy department for arm strengthening exercises and assessments of activities of daily living. Only 36 patients had had any follow-up
TABLE IV-Activities of daily living managed unaided

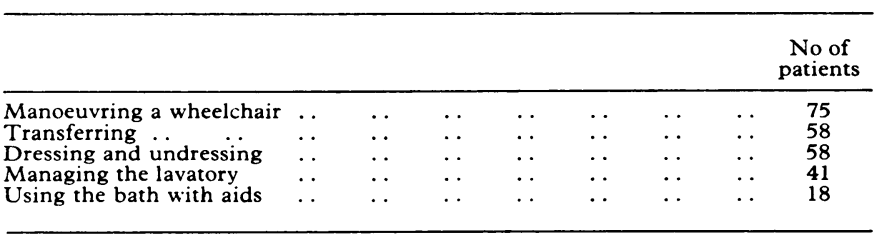

treatment during the very important interval between discharge from hospital and delivery of their first pair of pylons. Table IV shows the activities of daily living that could be managed unaided.

Those learning to use prostheses generally attended their own hospital physiotherapy department, either as inpatients or outpatients. Some attended the walking schools at Roehampton and Portsmouth limb fitting centres. The patients were taught to put on and take off their prostheses, walk inside and outside their home, stand up from chairs and sit down, and negotiate steps and slopes. At all stages most patients could manage to put on and take off their prostheses and walk indoors. Immediately activities such as walking outside, standing from chairs and sitting, and negotiating steps had to be carried out, the figures of those amputees coping independently dropped. More patients from the hospitals than from the limb fitting centres were given aids such as quadrupods. These obviously give more stability and support but require much more space and are particularly difficult in small areas.

\section{Discussion}

There is little point in supplying prostheses or even teaching a patient to use prostheses if he will never be able to put them on without help. For example, if he cannot dress unaided he will be unlikely to put on limbs. Yet if space at home is limited a wheelchair may also be of little use. Steps and stairs make easy mobility virtually impossible. Patients may be able to get upstairs using two handrails in the hospital physiotherapy department, only to have steep, narrow, twisting stairs with one banister at home.

Our survey showed that many patients' problems appeared to exist because home visits were made after the patient had been discharged. No forethought had gone into the future. In 44 cases no home visits had been made by the hospital staff. Small aids such as grab-rails, bath aids, etc, were immediately available and given (though they were not always used or necessary). Structural alterations were started far too late. Sometimes rehousing was necessary, and this was a lengthy procedure. None of this was satisfactory for patients who probably had only one or two years to live. ${ }^{9}$ Two-and-a-half years after the start of the project 21 patients had died.

Many stayed at home, not necessarily because they could not get out but because they had nowhere to go. Often friends' and neighbours' houses were impossible. Slipping on carpets, narrow doorways, and inaccessibility of the lavatory all presented problems. Visitors had to come to the amputee-friends, relatives, or regular social service support. The availability of day centres enabled the patient to have a change of scenery and an extension to a sometimes monotonous life.

Many amputees had been given prostheses, in some cases more than one pair. Some never achieved any use for them. Fourteen patients stopped wearing them immediately they left hospital. Had more been explained and more known about the social conditions fewer patients would have had to abandon artificial limbs so quickly. Perhaps it would have been more sensible to have withheld the supply of prostheses until the patient coped with his return home first.

Patients in residential care with plenty of space and help did not wear prostheses. Other residents in wheelchairs were faster and more mobile, and the amputee felt unsafe and slow. Only one patient had attempted to use artificial limbs in these favourable circumstances, and he had soon given up, opting for speed and safety in a wheelchair. Many who attempted to use 
artificial limbs had had to give up because it was too exhausting. ${ }^{210}$ Energy was required for other activities, such as cleaning, cooking, and generally looking after themselves, especially for patients living alone.

Some amputees found the use of prostheses invaluable. They wore them all day, did not like to be seen without them, and the prostheses were a definite part of them. The sense of achievement for these patients was enormous. Some of those using artificial limbs or having a wheelchair existence also had a reasonably functional and happy life. They showed that with intelligent and understanding help, and provided that they were physically able and motivated, life did have a positive meaning and was quite enjoyable.

Our data strongly indicate that little or no assessment had been made of these bilateral amputees. Patients went home unable to manage because of accommodation problems. Artificial limbs were automatically given with little thought of whether they could be used. Lifestyles and the wishes of the amputees were often not even considered. Mobility was the greatest problem. Little thought had gone into coping with any of the difficulties. The answer lies in better, total assessments-not just physical assessments but detailed examination of the patient's original lifestyle, his family circumstances, and accommodation. It should be natural for physiotherapists and occupational therapists to assess strength, mobility, balance, transfers, etc. If a patient cannot sit easily, dress, and transfer he is highly unlikely to put on artificial limbs without help. Respiratory and cardiac assessments must be also carried out during any physical exercise.

Assessment should not cease when the patient leaves hospital since circumstances change. Some amputees deteriorate physically once away from constant exercise and supervision; others improve dramatically once they are among their family.

Of the 65 patients in this series who were supplied with prostheses, 36 gave up using them. The reasons were in some cases obvious, but perhaps management teams should be readier to give amputees more useful pylons.

Short rocker pylons, though easy to use because of their reduced height, are difficult to use at home. They have no articulations (making sitting and manoeuvring a wheelchair difficult) and are cosmetically hideous. Why not give the bilateral amputee who is assessed as coping well articulated pylons, with even feet and shins, which would be more acceptable for the home and family?

The patient's lifestyle must be looked into with care and tact. Often little is known. Is the patient the leader in the family or the follower? Will he cope in residential care or would he be prepared to live alone? The patient's home circumstances must be investigated immediately he enters hospital. If alterations are required they must be organised quickly. If rehousing is necessary it takes time-if the patient wishes to move. His home may be hopeless, but he may be happier there than elsewhere.
All these assessments depend on more than one member of the rehabilitation-management team. Good communication is essential. If in the future assessments could be more standardised this should give a clearer and more positive approach to the total management of these patients. The International Classification of Impairments, Disabilities, and Handicaps might be used," or even a simple points system for each activity achieved with running totals might help.

It would have been impossible to complete this project without the help and co-operation from several people, and I am most grateful to Miss S M Adams, district physiotherapist, and all the staff at Queen Mary's Hospital, Roehampton, for their support; including Dr I H M Curwen, Mrs M Bresler, and Miss B C Davis, now district physiotherapist at King's College Hospital; Mrs C Partridge, health services research unit, University of Kent, Canterbury, for her encouragement and practical help, also Mrs B Wall who helped with coding and computing; the clerical staff at Roehampton, Portsmouth, and Brighton DHSS ALACs and LFCs for their help during the early stages of the project; Dr P C Puddifoot, special functions (ALAC) Roehampton for statistical DHSS information, and the BRADU Library for publications research; the artificial limb contractors (C A Blatchford and Sons Ltd, J E Hanger and Co Ltd, and Vessa Ltd) for their co-operation; the general practitioners, consultant surgeons, and medical officers for their support; the superintendent physiotherapists who worked so hard on the questionnaires, and also all the patients concerned in the project; the locally organised research scheme of the South-west Thames Regional Health Authority for funding the project; and finally, Mrs G Smith for all her support, encouragement, and clerical help throughout this project.

\section{References}

${ }^{1}$ Department of Health and Social Security Statistics and Research Division. Amputation statistics for England, Wales, and N Ireland 1979. Blackpool: DHSS, 1980.

" Kerstein MD, Zimmer H, Dugdale FE, Lerner E. Associated diagnoses which complicate rehabilitation of the patient with bilateral lower extremity amputations. Surg Gynecol Obstet 1975;140:875-6.

${ }^{3}$ Hamilton EA, Nichols PJR. Rehabilitation of the elderly lower-limb amputce. $\mathrm{Br}$ Med F 1972;ii:95-9.

+ Doherty SM, Nichols PJR. Non-prosthetic problems of rehabilitation of the ischaemic lower-limb amputee. Orthopaedics $1974 ; 7: 77-85$.

${ }^{5}$ McCollough NC. The bilateral lower extremity amputee. Orthop Clin North Am 1972;3:373-82.

${ }^{6}$ Hamilton A, Williams E, Nichols PJR. The elderly lower limb amputee. Update 1974;9:1641-50.

' Kegel B, Carpenter ML, Burgess EM. Functional capabilities of lower extremity amputees. Arch Phys Med Rehabil 1978;59:109-20.

8 Van de Ven CMC. A pilot survey of elderly bilateral lower limb amputees. Physiotherapy 1973;59:316-20.

${ }^{9}$ Brodie IA. Lower limb amputation. Br F Hosp Med 1970;4:596-604.

${ }^{10}$ Fisher SV, Gullickson G. Energy cost of ambulation in health and disability: a literature review. Arch Phys Med Rehabil 1978;59:124-33.

${ }^{11}$ World Health Organisation. International classification of impairments, disabilities, and handicaps. Geneva: WHO, 1980.

(Accepted 12 fune 1981)
Are there any recognised side effects of temazepam? Some of my patients taking this drug have complained variously of hallucinations at night and of ill-defined "unwell" feelings in the morning, vaguely related to giddiness and ataxia.

Although temazepam has a shorter half life than most other benzodiazepines, the side effects are similar. They include drowsiness and headache on waking; ataxia and incoordination; and hallucinations and confusion. ${ }^{1}$ Elderly patients appear to be more susceptible, partly because the half life of temazepam increases with age' but also because of an increased sensitivity to the effects of drugs on the central nervous system.

\footnotetext{
${ }^{1}$ Fowler LK. Post-marketing surveillance of Euhypnos (temazepam): a new hypnotic. F Int Med Res 1980;8:295-9.

${ }^{2}$ Huggett A, Flanagan RJ, Cook P, Grome P, Corless D. Chlormethiazole and temazepam. Br Med $\mathcal{f} 1981 ; 282: 475$.
}

A 3-year-old boy with no symptoms has on starting urination a pronounced ballooning of the foreskin that subsides as soon as the flow has started-as if pressure is required to force open the meatus. Can this be corrected by gentle retraction of the foreskin by the parents, who, until now, have been advised that they should never do this? At what age should parents attempt retraction of the foreskin?

The ballooning of the foreskin is due to nothing more than that at the moment of starting micturition the orifice of the foreskin is not lying exactly opposite the urinary meatus. The pressure of the stream of urine therefore balloons the foreskin and usually brings the two orifices close to each other. There is no need to do anything about it. Neither is there any need for the parents to attempt to retract the foreskin for the first four or five years or so: by that time the normal separation of the foreskin from the glans is almost always complete. 